\title{
Patterns and Variations of Snow Accumulation over Greenland, 1979-98, from ECMWF Analyses, and Their Verification
}

\author{
EDWARD HANNA \\ Institute of Marine Studies, University of Plymouth, Plymouth, Devon, United Kingdom \\ PAUl VAldes \\ Department of Meteorology, University of Reading, Reading, United Kingdom \\ JOSEPH MCCONNELL \\ Desert Research Institute, Reno, Nevada
}

(Manuscript received 28 February 2000, in final form 14 March 2001)

\begin{abstract}
ECMWF monthly climate analyses were used to retrieve surface temperature, precipitation, evaporation/ sublimation, and in conjunction with a simple meteorological model, snow accumulation over Greenland for 1979-98. The modeled snow accumulation is compared with existing observational maps of Greenland accumulation and mass balance, and with widely distributed coincident and contemporaneous ice-core data, primarily from NASA's Program in Arctic Regional Climate Assessment (PARCA) program. ECMWF-derived accumulation gave more realistic values for substantial (2-3-km elevation) areas of the "intermediate" inland plateau than previous methods, although the estimates are still $(\sim 20 \%-30 \%)$ too low over central Greenland. Overall, this ECMWF-driven model provides a reasonable first-order depiction, among the best currently available, of snow accumulation and its interannual variations. Mean annual ECMWF precipitation (snow accumulation) for the whole island (Greenland area $>2 \mathrm{~km}$ ) was $0.314(0.260) \mathrm{m} \mathrm{yr}^{-1}$, with standard deviations (demarcating interannual variation) of $0.108(0.098) \mathrm{m} \mathrm{yr}^{-1}$. The underlying cumulative $20-\mathrm{yr}$ changes in precipitation and accumulation of, respectively, +0.044 and $+0.019 \mathrm{~m} \mathrm{yr}^{-1}(20 \mathrm{yr})^{-1}$ are therefore insignificant, neither are there any striking trends for the individual monthly (January-December) series. However, in line with other recent results, accumulation decreased substantially in southeast and northwest Greenland and increased in the southwest and northeast. Notable $\left[\sim 2^{\circ}-4^{\circ} \mathrm{C}(20 \mathrm{yr})^{-1}\right]$ rises in $2-\mathrm{m}$ air temperature in April, September, and November, possibly related to changes in the length of the melt season, may have increased ablation of the ice sheet and require key attention in determining the surface mass balance.
\end{abstract}

\section{Introduction}

The surface mass balance (SMB) of the major ice sheets is of pressing concern in the climatic change arena and is the subject of major collaborative projects [e.g. the National Aeronautics and Space Administration's (NASA) Program in Arctic Regional Climate Assessment (PARCA)]. The amount of ice locked up in the Greenland ice sheet (GIS) is equivalent to $6-7 \mathrm{~m}$ of global sea level (Hvidberg 2000). Snow accumulation is the largest single contribution to the SMB of the GIS, although surface melting and rainfall are much more important components than for the Antarctic ice sheets. GIS accumulation is about twice the runoff and calving

Corresponding author address: Edward Hanna, Institute of Marine Studies, University of Plymouth, Drake Circus, Plymouth, Devon PL4 8AA, United Kingdom.

E-mail: e.hanna@plymouth.ac.uk rates, separately (Houghton et al. 1996), and on an interannual-decadal timescale seems to predominantly control surface elevation fluctuations at high $(>\sim 2 \mathrm{~km})$ altitudes on Greenland (McConnell et al. 2000a). Accumulation primarily depends on precipitation, and indeed the two distributions are generally similar inland, where there is little surface melting (Ohmura and Reeh 1991). Apart from surface temperature changes, changing climate could change circulation and precipitation (and hence accumulation) patterns over Greenland (Houghton et al. 1996). Changes in the frequency and intensity of transitory cyclones are paramount for precipitation trends, while the precipitation (accumulation)-temperature relation is quite complex (Bromwich et al. 1993). Because of the lack of widespread surface data over Greenland, climate analyses-such as those of the European Centre for Medium-Range Weather Forecasts (ECMWF) and National Centers for Environmental Prediction-National Center for Atmospheric Re- 
(a)

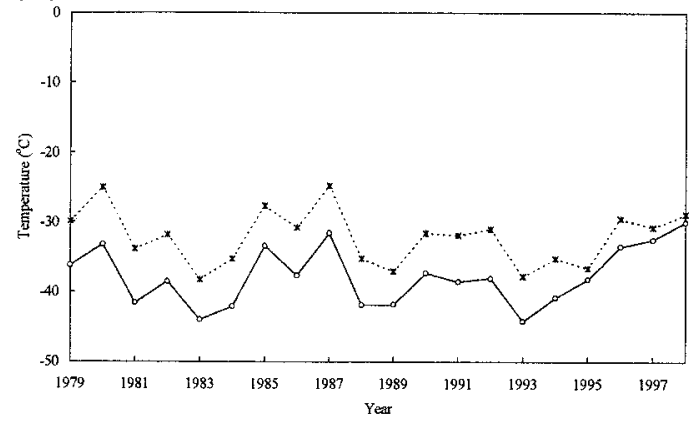

(c)

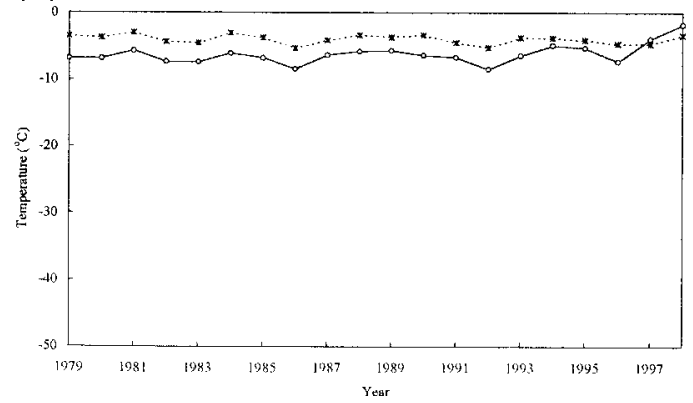

(b)

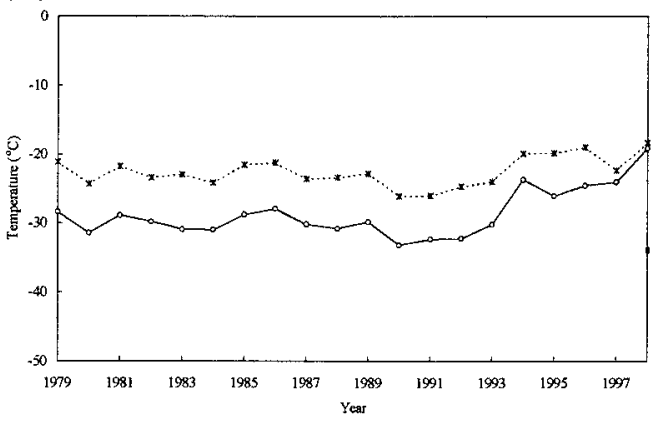

(d)

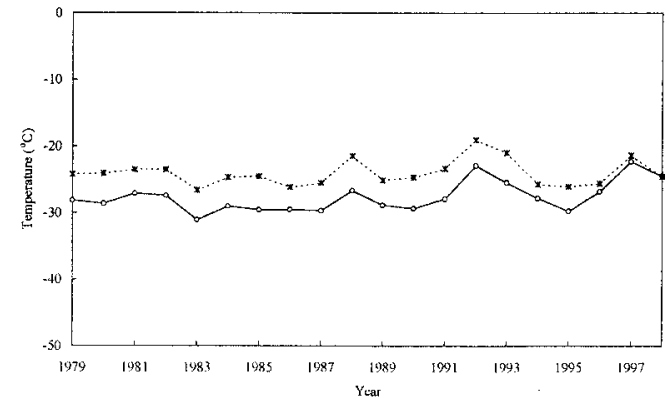

FIG. 1. ECMWF (solid line with circles) and NCEP-NCAR (dashed line with stars) analyses' Greenland 2-m air temperature 1979-98 for (a) Jan, (b) Apr, (c) Jul, and (d) Oct.

search (NCEP-NCAR)—provide geographically even "climatologies," including hitherto inaccessible regions. However, their accuracy, including spatial and temporal consistency, needs checking. This can be done by cross-comparing the analyses as well as by validation with in situ data.

Climate analyses are forecast models that fit observations available in near-real time to a prognostic firstguess field, typically in a 6-h cycle. Reanalyses additionally use a fixed model scheme (to avoid climatic drift due to model changes) and assimilate observations in retrospect (i.e., those that later become available). In principle, this should make them superior to operational analyses, but this is by no means certain because there are relatively few observations over Greenland and treatment of ice physics is rudimentary.

Both the ECMWF and NCEP-NCAR analyses are based on global spectral models (ECMWF 1995; Gibson et al. 1997).

The versions of the global atmospheric model used to compile the ECMWF analyses used in this study had horizontal spectral resolutions of T106 [the ECMWF reanalysis (ERA) from January 1979 to February 1994], T213 (operational analyses from March 1994) and T319 (later analyses from April 1998). There were 31 vertical layers: 6 in the boundary layer, with the lowest layer 4 $\mathrm{hPa}$ from the surface. The computational time step was 15 min (30 min for ERA), used to compile 6-h analyses and 24-h forecasts, on which the monthly averages we use are based. Snow falling through atmospheric layers with a temperature greater than $2^{\circ} \mathrm{C}$ was made to melt to rain. The snow cover analysis strongly depended on observations (as well as persistence and climatology), so the water mass budget of the hydrological cycle is not closed for the snow phase. Surface thermal properties depend on snow depth (effectively snow water equivalent) but not age. The maximum allowed snow albedo was 0.80 , and ice albedo was fixed at 0.70 (P. Kållberg 1999, personal communication).

The NCEP-NCAR reanalysis model has a horizontal resolution of T62 $(209 \mathrm{~km})$ and 28 vertical levels: 5 in the boundary layer, with the lowest layer $\sim 5 \mathrm{hPa}$ from the surface. [Information obtained from the NCAR Data Support Section Web site (http://dss.ucar.edu/pub/ reanalysis.)] Dynamics and physics were computed at a time step of $20 \mathrm{~min}$, and atmospheric radiation was fully calculated every $3 \mathrm{~h}$. These were averaged for 6$\mathrm{h}$ predictions used to calculate the monthly mean flux fields. Snowfall (rather than rain) occurred "if a linear combination of ground temperature (weighted 0.35 ) and the temperature at the lowest atmospheric level (weighted 0.65$)$ is $<0^{\circ} \mathrm{C}$." Snow cover was estimated from weekly Joint Ice Center satellite imagery, and-because of lack of observations-snow depth was assumed to be a simple function of 2-m temperature and therefore somewhat arbitrary. As with the ECMWF analyses, the snow/water budget is not strictly balanced (W. Ebisuzaki 1999, personal communication). Permanent snow has a set albedo of 0.75 if poleward of $70^{\circ}$, and 0.60 if equatorward of $70^{\circ}$ and $\geq 1 \mathrm{~cm}$ deep (depending on back- 
TABLE 1. Mean, SD, and underlying cumulative 20-yr change of 2-m air temperature averaged over Greenland in ERA/ECMWF analyses and NCEP-NCAR reanalysis for 1979-98.

\begin{tabular}{|c|c|c|c|c|c|c|}
\hline & \multicolumn{2}{|c|}{ Mean $\left({ }^{\circ} \mathrm{C}\right)$} & \multicolumn{2}{|c|}{$\mathrm{SD}\left({ }^{\circ} \mathrm{C}\right)$} & \multicolumn{2}{|c|}{ Cumulative change $\left[{ }^{\circ} \mathrm{C}(20 \mathrm{yr})^{-1}\right]$} \\
\hline & ECMWF & NCEP-NCAR & ECMWF & NCEP-NCAR & ECMWF & NCEP-NCAR \\
\hline$\overline{\mathrm{Jan}}$ & -37.75 & -32.14 & 4.26 & 3.96 & 3.09 & -1.64 \\
\hline Feb & -38.48 & -32.36 & 2.91 & 3.33 & 1.93 & -1.64 \\
\hline Mar & -36.81 & -30.41 & 3.00 & 3.00 & 1.87 & -2.25 \\
\hline Apr & -28.64 & -22.50 & 3.54 & 2.17 & 6.41 & 2.27 \\
\hline May & -18.04 & -12.59 & 3.05 & 1.81 & 5.36 & 0.84 \\
\hline Jun & -9.41 & -5.30 & 2.27 & 0.87 & 3.77 & 0.23 \\
\hline Jul & -6.25 & -4.01 & 1.51 & 0.66 & 2.42 & -0.51 \\
\hline Aug & -10.05 & -8.00 & 1.71 & 1.15 & 2.20 & -0.78 \\
\hline Sep & -18.81 & -16.16 & 2.21 & 1.48 & 4.49 & 1.99 \\
\hline Oct & -27.60 & -24.00 & 2.32 & 1.98 & 3.88 & 0.99 \\
\hline Nov & -32.08 & -27.83 & 3.35 & 2.68 & 7.04 & 3.69 \\
\hline Dec & -36.00 & -30.97 & 3.29 & 2.25 & 5.83 & 2.10 \\
\hline Year & -24.99 & -20.52 & 2.79 & 2.11 & 4.02 & 0.44 \\
\hline
\end{tabular}

ground and snow albedo and fractional snow cover if shallower).

Both analyses use the U.S. Navy 10 arc min orography, which is deficient over Greenland when compared with the definitive Ekholm/Kort-og Matrikelstyrelsen digital elevation model (DEM; Bromwich et al. 1998; Hanna and Valdes 2001). However, recent versions of the ECMWF analyses, especially since April 1998, have used a much improved orography scheme.

When dealing with ECMWF analyses, one has little choice but to use post-ERA (operational) data after February 1994 . The reliability of trends in ERA and postERA data is questionable. Even within ERA there are "nonclimatic" drifts due to changes in the observations, which might be as large or larger than real climatic drifts. Great care must be taken when trying to use ERA and post-ERA analyses for "climate trends" (Bromwich 1999; Stendel and Bengtsson 1999).

Further problems could arise from changes made to the model's boreal albedo and surface boundary layer scheme (Kållberg 1997). According to P. Kållberg:

For the permanent ice sheets, there has been an important change in the boundary layer parameterisation that prevents the excessively cold skin temperatures in ERA over these areas. . The ERA15 turbulence scheme basically turned off any heat transfer between air and ice/snow when very cold. Hence the surface temperature, i.e. in the uppermost part of the ice, was essentially in radiative balance (and equal to the skin temperature).

In preparation for ERA40 we have now tested a revised scheme. . Over Greenland the revised turbulence yields up to $9^{\circ} \mathrm{C}$ warmer 2-m temperature. The 2-m temperature in ECMWF is interpolated (following a Businger profile) between the lowest model level [ $\sim 30 \mathrm{~m}$ above the model surface] and the temperature in the top surface layer.

Specific changes to the ECMWF model boundary layer/ surface parameterization include changes to the surface energy coefficients of heat, moisture, and momentum in statistically stable situations (Viterbo et al. 1999), ef- fective from 19 September 1996. The snow albedo of the permanent snow-covered areas (including the ice sheets) was altered from 0.8 to 0.7 on 10 December 1996 (Viterbo and Betts 1999). Macrorelief (surface undulations with wavelengths $\sim 5-30 \mathrm{~km}$ ) affects boundary layer airflow, and there is a feedback of resulting snowdrift on surface topography and spatial accumulation (van der Veen and Bolzan 1999). We put this forward as an example of a (subpixel scale) process that is probably important to get right in the model.

Genthon and Braun (1995) studied ECMWF operational analyses spanning 1985-91 for Greenland and found over-high interannual surface temperature variability in the center as compared with infrared satellite data: they surmised that this might have been caused by changes in the model and input observations. Despite excessive coastal precipitation and suspected low inland accumulation compared with observations, GIS mean accumulation agreed very well with previous estimates. Small-scale precipitation features agreed well with those in Ohmura and Reeh (1991). Genthon and Braun (1995) reckoned that model analysis and control of atmospheric moisture, temperature, and transport near the observatories (mainly around the Greenland coast) should help to constrain forecast precipitation (the latter does not directly use observations). Their conclusion was that “... the ECMWF model does a fairly good job with atmosphere-surface water exchange over ice sheets. . . Even a moderate improvement over the currently available product will yield a much needed, easy to use, fullcoverage, gridded climatology of the climate over Greenland. .."

In a previous validation study, two of us compared monthly ECMWF operational analyses and reanalysis spanning 1979-98 with all available surface climate data for Greenland (Hanna and Valdes 2001). Analyzed air temperatures generally agreed well with in situ values once deficiencies in model orography (mainly leading to a cold bias around the coast) were corrected. Model forecast precipitation was also physically plau- 
(a)

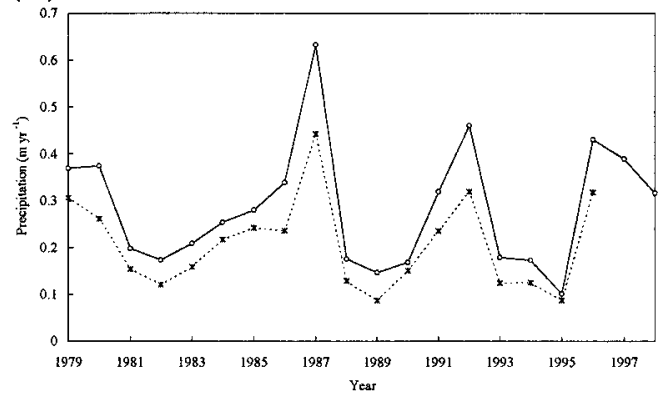

(c)

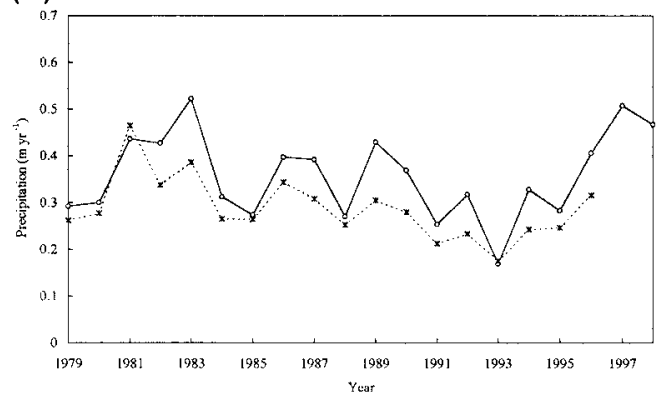

(b)

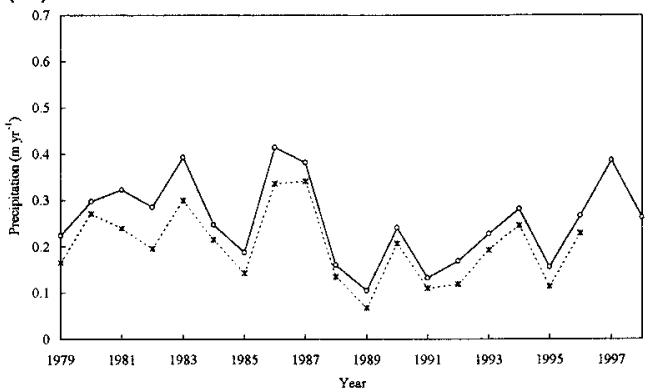

(d)

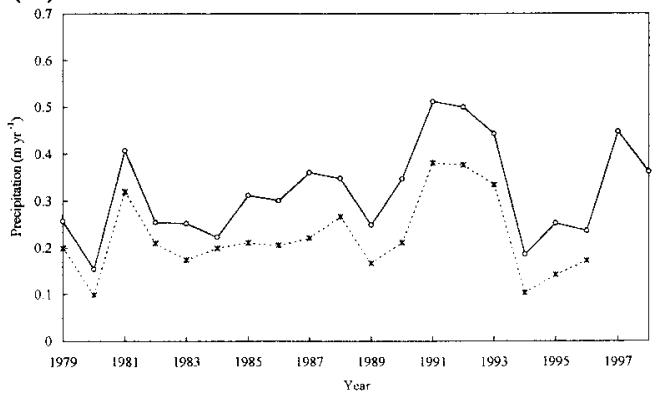

FIG. 2. Same as Fig. 1 but for total precipitation, including the corrected precipitation fields (available to 1996) from the NCEP-NCAR reanalysis.

sible, with amounts about one-third larger than observed, uncorrected coastal data (at least the sign of this difference is right in view of considerable rain/snow gauge catch losses caused by prevailing strong katabatic winds). ECMWF analyses captured well the interannual variability occurring at surface stations.

Bromwich et al. (1998) reviewed precipitation retrieval methods over the GIS. These included ECMWF operational analysis moisture budget, ERA (at $2.5^{\circ}$ resolution) and two versions of the NCEP-NCAR reanalysis, and two enhanced precipitation retrieval [Keen and Chen-Bromwich (C-B)] models. The $\mathrm{C}-\mathrm{B}$ model uses ECMWF operational analyses at $2.5^{\circ}$, a high-resolution Greenland topography, and the equivalent geopotential in $\sigma$ coordinates to compute vertical air motion, moisture advection and condensation, and hence precipitation on a $(50 \mathrm{~km})^{2}$ grid. The strength of the C-B approach is its relatively high horizontal resolution. However, the disadvantage is that the vertical motion is calculated using only an approximate form of the governing equations. It is therefore important to reconsider the ECMWF data using a higher-resolution version of the ERA dataset.

Bromwich et al.'s (1998) ERA and C-B average spatial distribution maps (their Figs. 4c,b,f) are superficially quite similar and, when compared with glaciological accumulation data, both show a precipitation shortfall over the interior plateau. There are inevitable scaling problems in comparing ERA at $\left(2.5^{\circ}\right)^{2}$ (a considerably lower resolution than we use in this study) with $\mathrm{C}-\mathrm{B}$ at $(50 \mathrm{~km})^{2}$. This resolution difference might have smeared ERA precipitation maxima, especially around the northern edge of Greenland, relative to $\mathrm{C}-\mathrm{B}$. Taking this into account, the precipitation distribution maps could be interpreted as being virtually identical. Moreover, the C-B results depend partly on the quality of the input (ECMWF) analyses. Therefore, we consider it important to investigate whether the more recent higher-resolution ECMWF data improves upon the lowerresolution data and the $\mathrm{C}-\mathrm{B}$ method.

McConnell et al. (2000b) compared C-B modeled precipitation with new ice-core accumulation data for 11 reasonably well-distributed sites on the intermediate plateau, mainly above $2 \mathrm{~km}$, surrounding but not within central Greenland. They derived scalars to link modeled precipitation, which was ubiquitously too low, to mean annual accumulation. It is clear that ECMWF data should also be subjected to testing against the McConnell et al. (and other ice core) data.

Here we correct ECMWF surface climate fields for changes in model orography, provide updated series of Greenland precipitation and snow accumulation, and compare the latter with the best available observational accumulation and SMB maps (derived from in situ and satellite data) and all available coincident and contemporaneous ice-core data.

\section{Recent behavior of Greenland surface temperature, precipitation, and snow accumulation}

We used monthly ERA (Jan 1979-Feb 1994) and operational ECMWF analyses (Mar 1994-Dec 1998) to 
compile time series of 2-m surface air temperature, total (stratiform plus convective) precipitation, surface latent heat flux (SLHF) and, from these parameters, snow accumulation over Greenland. We define snow accumulation as the difference between solid precipitation and evaporation/sublimation (Appenzeller et al. 1998). The ECMWF analyses surface fields used here are those interpolated by Berrisford et al. (1998) onto a $320 \times$ 160 pixel $\left[\left(\sim 1.125^{\circ}\right)^{2}\right]$ regular global grid.

Based on previous studies, we assumed a sensitivity of Greenland surface temperature to change in elevation of $-8^{\circ} \mathrm{C} \mathrm{km}^{-1}$ (Hanna and Valdes 2001), used to correct ECMWF and NCEP-NCAR analyses' air temperature for deficiences in model orography compared with the Ekholm DEM. After consulting with the staff at ECMWF, precipitation and SLHF were not adjusted, as there are competing effects with precipitation. On the one hand, lower atmospheric moisture at high altitudes (due to lower temperatures) should yield lower precipitation. Orographic forcing and moisture convergenceespecially around the steep coastal margin-may work against this, so the relation is by no means clear. Precipitation is also greatly influenced (again mainly in the coastal regions) by subpixel-scale local orography. Radiation and soil moisture are more important than the atmospheric moisture deficit for latent heat flux and evaporation (A. Beljaars 1999, personal communication).

Figures 1 and 2 show interannual series of ECMWF and NCEP-NCAR analyses' surface temperature and precipitation series for Greenland for four seasonally representative months of the year. We used the corrected precipitation fields from the NCEP-NCAR reanalysis, to minimize (but not eliminate) spatial shortcomings in simulated precipitation patterns over Greenland (Bromwich et al. 1998). These improved NCEP-NCAR precipitation data were only available to 1996 . Based on the results of Bromwich et al. (1998) and the author, EH's, own analysis, NCEP-NCAR analyzed precipitation is markedly too low over much of Greenland, so was not used to compile an additional snow accumulation series. The sole purpose of the NCEP-NCARcorrected precipitation fields here is to show the broad agreement in temporal fluctuations (i.e., interannual variability) in Greenland-averaged precipitation between the two independent (ECMWF and NCEP-NCAR) climate analyses.

All these data are for a fixed area of Greenland (nearly all of it apart from some outlying coastal pixels) that was classified as "land" throughout several changes in the ECMWF model's land/sea mask. This consistency is desirable because surface air temperature and precipitation fluxes typically exhibit steep gradients near the Greenland coast, so sporadic "ocean" pixels were not allowed to contaminate any part of the series. The area used is also almost contiguous with (although slightly larger than) the GIS, which covers $82 \%$ of the island (Ohmura et al. 1999). In practice, a sensitivity study
TABLE 2. Mean, SD, and underlying cumulative 20-yr change of total precipitation averaged over Greenland in ERA/ECMWF analyses for 1979-98.

\begin{tabular}{cccc}
\hline \hline Period $(\mathrm{pd})$ & $\begin{array}{c}\text { Mean } \\
\left(\mathrm{m} \mathrm{pd}^{-1}\right)\end{array}$ & $\begin{array}{c}\mathrm{SD} \\
\left(\mathrm{m} \mathrm{pd}^{-1}\right)\end{array}$ & $\begin{array}{c}\text { Cumulative change } \\
\left(\mathrm{m} \mathrm{pd}^{-1} / 20 \mathrm{yr}^{-1}\right)\end{array}$ \\
\hline Jan & 0.024 & 0.011 & 0.001 \\
Feb & 0.022 & 0.009 & -0.005 \\
Mar & 0.021 & 0.008 & 0.000 \\
Apr & 0.021 & 0.007 & -0.004 \\
May & 0.024 & 0.008 & 0.008 \\
Jun & 0.025 & 0.007 & 0.001 \\
Jul & 0.030 & 0.008 & 0.001 \\
Aug & 0.035 & 0.012 & 0.008 \\
Sep & 0.030 & 0.010 & 0.011 \\
Oct & 0.027 & 0.009 & 0.010 \\
Nov & 0.029 & 0.009 & 0.006 \\
Dec & 0.025 & 0.009 & 0.009 \\
Year & 0.314 & 0.108 & \\
\hline
\end{tabular}

showed that derived climatic patterns were relatively insensitive to slight changes in the selected land mask.

Surface air temperature is important, primarily because it determines the rain/snow and evaporation/sublimation thresholds and hence the snow accumulating in model pixels. Correlation coefficients between interannual $(20 \mathrm{yr})$ temperature series of ECMWF and NCEP-NCAR analyses ranged from 0.50 in July to 0.89 in April and November, with an annual mean of 0.78; they were always statistically significant at the $95 \%$ level $(\alpha<0.05)$. Mean monthly 2 -m air temperature for Greenland ranged from $-38.48^{\circ} \mathrm{C}\left(-32.36^{\circ} \mathrm{C}\right)$ in February to $-6.25^{\circ} \mathrm{C}\left(-4.01^{\circ} \mathrm{C}\right)$ in July in the ECMWF (NCEP-NCAR) analyses (Table 1). Mean annual temperature was $4.47^{\circ} \mathrm{C}$ lower for the ECMWF than NCEPNCAR analyses. This ECMWF "cold bias" was somewhat less for the Greenland area $<1 \mathrm{~km}$ elevation $\left(3.09^{\circ} \mathrm{C}\right)$ but emphasized for the area $>2 \mathrm{~km}\left(5.47^{\circ} \mathrm{C}\right)$. It ranged from $2.05^{\circ} \mathrm{C}$ in August to $6.40^{\circ} \mathrm{C}$ in March for the whole island, although the area $<1 \mathrm{~km}$ was actually slightly warmer in July and August in the ECMWF analyses. The GIS is around its seasonal coldest in March, when enhanced subsidence over the high plateau could have exacerbated any deficiencies in the ECMWF model's boundary layer scheme.

Least squares linear regression trend-line analysis was used to derive underlying cumulative 20-yr changes (CCs) in temperature, precipitation, and accumulation for Greenland. The CCs in temperature for each month were always positive in the ECMWF analyses and often strongly so $\left[\sim 3^{\circ}-7^{\circ} \mathrm{C}(20 \mathrm{yr})^{-1}\right]$, most probably due to likely correction of the cold bias in later ECMWF operational analyses (Table 1). This is seen as a warming relative to NCEP-NCAR temperatures (Fig. 1). The $\mathrm{CCs}$ were about $3^{\circ}-4^{\circ} \mathrm{C}(20 \mathrm{yr})^{-1}$ lower, and sometimes negative, in the NCEP-NCAR reanalysis. Both analyses agreed well (correlation $r=0.93 ; \alpha<0.001$ ) in terms of which months showed the least and greatest CCs. Overall (annual) CCs were $+4.02^{\circ} \mathrm{C}(20 \mathrm{yr})^{-1}$ for the ECMWF analyses and $+0.44^{\circ} \mathrm{C}(20 \mathrm{yr})^{-1}$ for the 
TABLE 3. Details (including site locations and periods) of PARCA ice-core data used in this study.

\begin{tabular}{lcccc}
\hline \hline \multicolumn{1}{c}{ Site } & $\begin{array}{c}\text { Lat } \\
\left({ }^{\circ} \mathrm{N}\right)\end{array}$ & $\begin{array}{c}\text { Long } \\
\left({ }^{\circ} \mathrm{W}\right)\end{array}$ & $\begin{array}{c}\text { Elev } \\
(\mathrm{m})\end{array}$ & Period \\
\hline 1 (South Dome) & 63.2 & 44.8 & 2850 & $1979-96$ \\
2 (Saddle Ndye3) & 66.0 & 44.5 & 2460 & $1979-96$ \\
3 (665_425) & 66.5 & 42.5 & 2381 & $1981-96$ \\
4 (South Tunu) & 69.8 & 35.0 & 2650 & $1979-96$ \\
5 (NASA East) & 75.0 & 30.0 & 2631 & $1979-96$ \\
6 (71_47) & 71.1 & 47.2 & 2134 & $1979-96$ \\
7 (72_475) & 71.9 & 47.5 & 2277 & $1979-96$ \\
8 (NASA-U) & 73.8 & 49.5 & 2368 & $1979-92$ \\
9 (75_51) & 75.0 & 51.0 & 2200 & $1979-96$ \\
$10\left(76 \_53\right)$ & 76.0 & 53.0 & 2200 & $1979-96$ \\
11 (Humboldt M) & 78.5 & 56.8 & 1973 & $1979-92$ \\
6345 & 63.8 & 45.0 & 2733 & $1979-97$ \\
6745 & 67.5 & 45 & 2250 & $1984-97$ \\
6839 & 68.5 & 39.5 & 2787 & $1985-97$ \\
6841 & 68.0 & 41.0 & 2639 & $1987-97$ \\
6938 & 69.0 & 38.0 & 2920 & $1983-97$ \\
6939 & 69.6 & 39.0 & 2954 & $1982-97$ \\
6941 & 69.4 & 41.0 & 2764 & $1985-97$ \\
6943 & 69.2 & 43.0 & 2499 & $1979-97$ \\
6945 & 69.0 & 45.0 & 2148 & $1979-97$ \\
7145 & 71.5 & 45.0 & 2615 & $1986-97$ \\
7245 & 72.25 & 45.0 & 2770 & $1984-97$ \\
7345 & 73.0 & 45.0 & 2815 & $1979-97$ \\
736472 & 73.6 & 47.2 & 2600 & $1980-97$ \\
\hline
\end{tabular}

NCEP-NCAR reanalysis. Considering the relatively low and statistically insignificant value from the latter (from a series that is meant to be more self consistent), we surmise that there was no significant change in the mean temperature of the GIS over the two decades. The month with the greatest $\mathrm{CC}$ in temperature (a strong rise) was November $\left[7.04^{\circ} \mathrm{C}(20 \mathrm{yr})^{-1}\right.$ in ECMWF analyses and $3.69^{\circ} \mathrm{C}(20 \mathrm{yr})^{-1}$ in the NCEP-NCAR reanalysis]. This can be regarded as interesting, if not quite statistically significant, in that it was well above the respective standard deviations (SDs) for that month $\left(3.35^{\circ} \mathrm{C}\right.$ in ECMWF analyses and $2.68^{\circ} \mathrm{C}$ in the NCEPNCAR reanalysis). April and September experienced marginally notable $(>1 \sigma)$ temperature rises. The September and November rises were noteworthy in both analyses for both the areas $<1 \mathrm{~km}$ and $>2 \mathrm{~km}$, while the April rise was noteworthy in both analyses at $<1$ $\mathrm{km}$ but not at $>2 \mathrm{~km}$. The month with the least positive $\mathrm{CC}$ in temperature was March $\left[1.87^{\circ} \mathrm{C}(20 \mathrm{yr})^{-1}\right.$ for ECMWF and $-2.25^{\circ} \mathrm{C}(20 \mathrm{yr})^{-1}$ for NCEP-NCAR].

Mean annual precipitation ( \pm 1 SD of the annual values) from the ECMWF analyses was $0.314( \pm 0.108) \mathrm{m}$ $\mathrm{yr}^{-1}$. This is a little lower than the $0.36 \mathrm{~m} \mathrm{yr}^{-1}$ reported for ERA (1979-93) data for Greenland by Appenzeller et al. (1998), probably because we miss parts of the relatively wet coastal fringe (see above discussion on the ECMWF land/sea mask). Mean monthly values ranged from $0.021 \mathrm{~m}$ in March to $0.035 \mathrm{~m}$ in August (Table 2). ECMWF analyses' mean annual precipitation was $0.260 \mathrm{~m} \mathrm{yr}^{-1}$ for the area $>2 \mathrm{~km}$.

Precipitation and accumulation series for Greenland have characteristic coefficients of variation, whereby
SDs tend to approximate a quarter of the respective mean values (Braithwaite 1994) (see Figs. 2 and 3). Apart from natural random noise, this may reflect interannual circulation changes between Icelandic and Labrador Sea cyclonic regimes, respectively, yielding relatively light and heavy precipitation over Greenland (Chen et al. 1997). These authors propose a possible feedback that may occur between GIS accumulation (and hence topography) and cyclonic activity, especially regarding (orographically forced) lee cyclogenesis off southeast Greenland, which reportedly produces many of the Icelandic cyclones. Unambiguous underlying trends (i.e., those that could be attributed to climatic change) would need to exceed this interannual variability.

The underlying CC in ECMWF analyses annual precipitation for all Greenland was $+0.044 \mathrm{~m} \mathrm{yr}^{-1}(20$ $\mathrm{yr})^{-1}$, which is considerably less than the SD of 0.108 $\mathrm{m} \mathrm{yr}^{-1}$ (a measure of interannual variability in all the months' worth of data) and hence totally insignificant. The May, September, and October series had underlying increases of $0.008,0.011$, and $0.010 \mathrm{~m} \mathrm{month}^{-1}(20$ $\mathrm{yr})^{-1}$ in precipitation, which are barely significant $(1 \sigma$ level) based on their respective SDs $(0.008,0.010$, and $0.009 \mathrm{~m} \mathrm{month}^{-1}$ ). The significant downward trend in Greenland-averaged precipitation from 1985 to 1995 (Bromwich et al. 1999) was followed by an increase (Fig. 2), nullifying trends for our longer period. As in Bromwich et al. (1999) and based on our updated precipitation series, we see a significant correlation of Greenland precipitation in winter with the North Atlantic oscillation (NAO) index: negative for the island as a whole and in the center, south and west, and positive in the east.

SLHF (used for calculating evaporation/sublimation) is considered positive down toward the surface, so positive fluxes indicate deposition of moisture (condensation) onto the surface, while negative fluxes indicate evaporation or sublimation. ECMWF analyses' mean monthly SLHF for all of Greenland averaged $-2.13 \mathrm{~W}$ $\mathrm{m}^{-2}$, with a seasonal range from $0.75 \mathrm{~W} \mathrm{~m}^{-2}$ in February to $-10.35 \mathrm{~W} \mathrm{~m}^{-2}$ in July. However, there was very little sublimation/evaporation in the ECMWF analyses on the high plateau $(>2 \mathrm{~km}$ ) in summer (SLHF only $-3.68 \mathrm{~W} \mathrm{~m}^{-2}$ in Jul).

It is difficult to say whether one would expect net sublimation (condensation) of moisture off (onto) the GIS surface in winter. This is due to the lack of reliable observational data relating to the boundary layer temperature profile, radiation divergence, blowing snow, and roughness length (R. J. Braithwaite 1999, personal communication). However, some results have been submitted based on Greenland Climate Network AWS data (K. Steffen 1999, personal communication). Recent Arctic validation studies (Cullather et al. 2000; Bromwich et al. 2000) suggest that the ECMWF evaporation values are more realistic than those in the NCEP-NCAR reanalysis, at least in terms of their spatial distribution, 
(a)

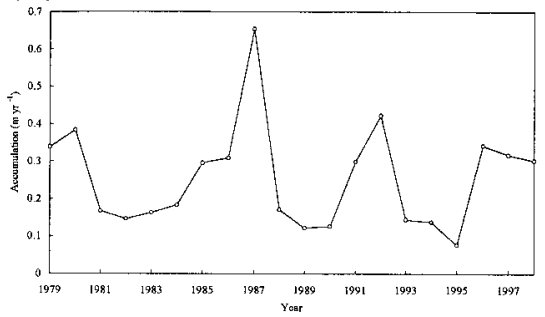

(c)

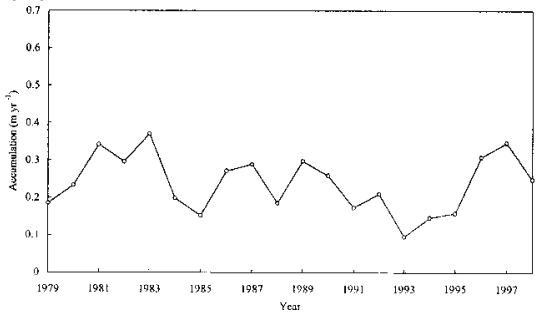

(b)

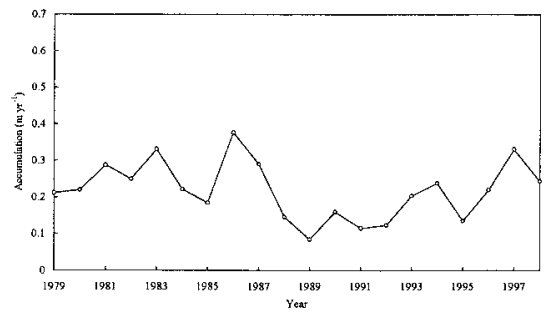

(d)

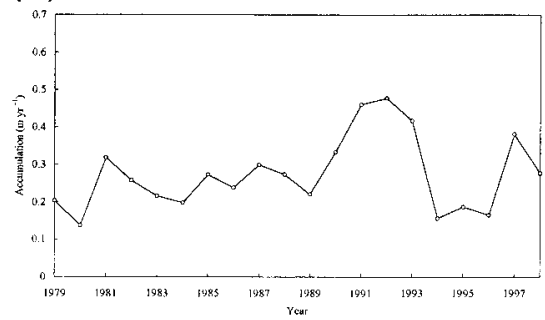

FIG. 3. ECMWF analyses' snow accumulation for the area of Greenland $>2 \mathrm{~km}$ elevation, for (a) Jan, (b) Apr, (c) Jul, and (d) Oct 1979-98.

although perhaps they are too high. Differences and deficiencies in model boundary layer schemes may strongly bias SLHF.

Our final set of figures relates to the interannual series of snow accumulation from our ECMWF-driven model (Fig. 3). We do not currently account for snowmelt, which is very substantial in the lower marginal zones of the GIS-especially in the south. Thus the following figures are of accumulation for the area of Greenland $>2 \mathrm{~km}$ elevation (according to the Ekholm DEM), where snowmelt is either negligible or mostly percolates into the underlying snow and refreezes (Krabill et al. $2000)$. Mean annual accumulation ( \pm 1 SD of the annual values) was $0.260( \pm 0.098) \mathrm{m} \mathrm{yr}^{-1}$. This is practically the same as precipitation $>2 \mathrm{~km}$ and suggests that runoff in this region is indeed a relatively small component of the SMB. Mean monthly accumulation values ranged from $0.017 \mathrm{~m}$ in March to $0.028 \mathrm{~m}$ in August, with a secondary peak of $0.025 \mathrm{~m}$ in November attributed to relatively high autumn precipitation and low evaporation. Relatively strong midsummer evaporation suppressed accumulation in June and July.

The underlying $\mathrm{CC}$ in snow accumulation $(>2 \mathrm{~km})$ was $0.019 \mathrm{~m} \mathrm{yr}^{-1}(20 \mathrm{yr})^{-1}$, which was insignificant. Monthly profiles and CCs for the two decades tend to mirror those for precipitation. On the whole, accumulation seems to have held steady or declined slightly in spring and increased somewhat in autumn and early winter. However, based on SD values, none of the CCs for the months were at all statistically significant. Due to high interannual variability of snow accumulation over Greenland, many more years' worth of climate (analyses, in situ, and ice core) data will be needed to discern any significant trends.

\section{Verification of ECMWF-modeled snow accumulation}

a. Comparison with existing snow accumulation and mass balance maps

To verify our model results on the broad (Greenland) scale, we used two key existing observation-based Greenland snow accumulation maps.

1) $\mathrm{A} 0.02^{\circ}$ lat $\times 0.05^{\circ}$ long accumulation map (grid) compiled by P. Calanca (Swiss Federal Institute of Technology), based on numerous ice-core data (Calanca et al. 2000). These data are from Ohmura and Reeh (1991) and Ohmura et al. (1999).

2) $\mathrm{A}(50 \mathrm{~km})^{2}$ accumulation map calculated from satellite-derived firn emissivity (Zwally and Giovinetto 2000).

These maps show very similar $( \pm 5 \%)$ accumulation amounts within the dry snow zone and upper percolation facies (i.e., much of the interior of Greenland). Close to and outside the equilibrium line (where net mass accumulation at the surface is zero), that is, within $\sim 100$ $\mathrm{km}$ of the terminus, the Calanca map shows gross snow accumulation rather than net accumulation (M. B. Giovinetto 2000, personal communication). On the other hand, the Zwally and Giovinetto (2000) map seems to be a good approximation of net mass accumulation at the surface across the whole of the GIS. Net snow accumulation includes losses such as surface melt runoff, while gross accumulation is more akin to precipitation. However, this "edge effect" distinction between the two maps is unlikely to affect the present analysis, due to the relatively coarse ECMWF-grid resolution. Our ECMWF-modeled snow accumulation (which accounts 
(a)

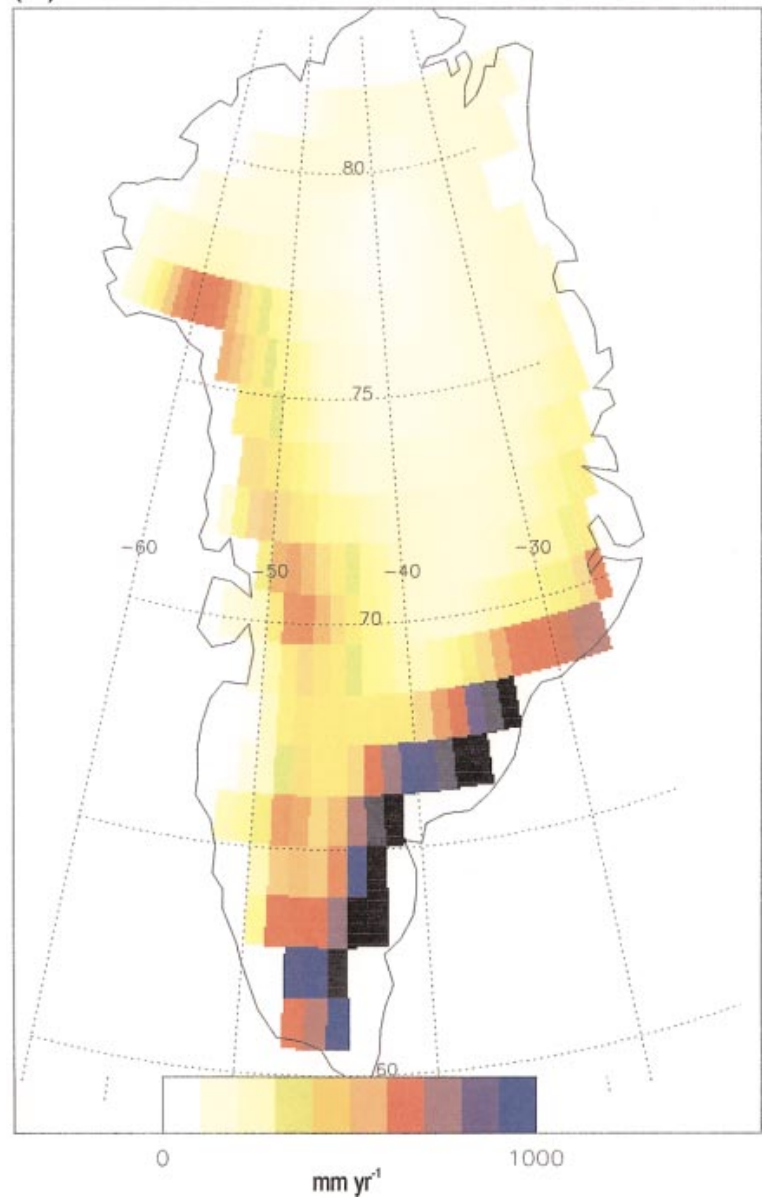

(b)

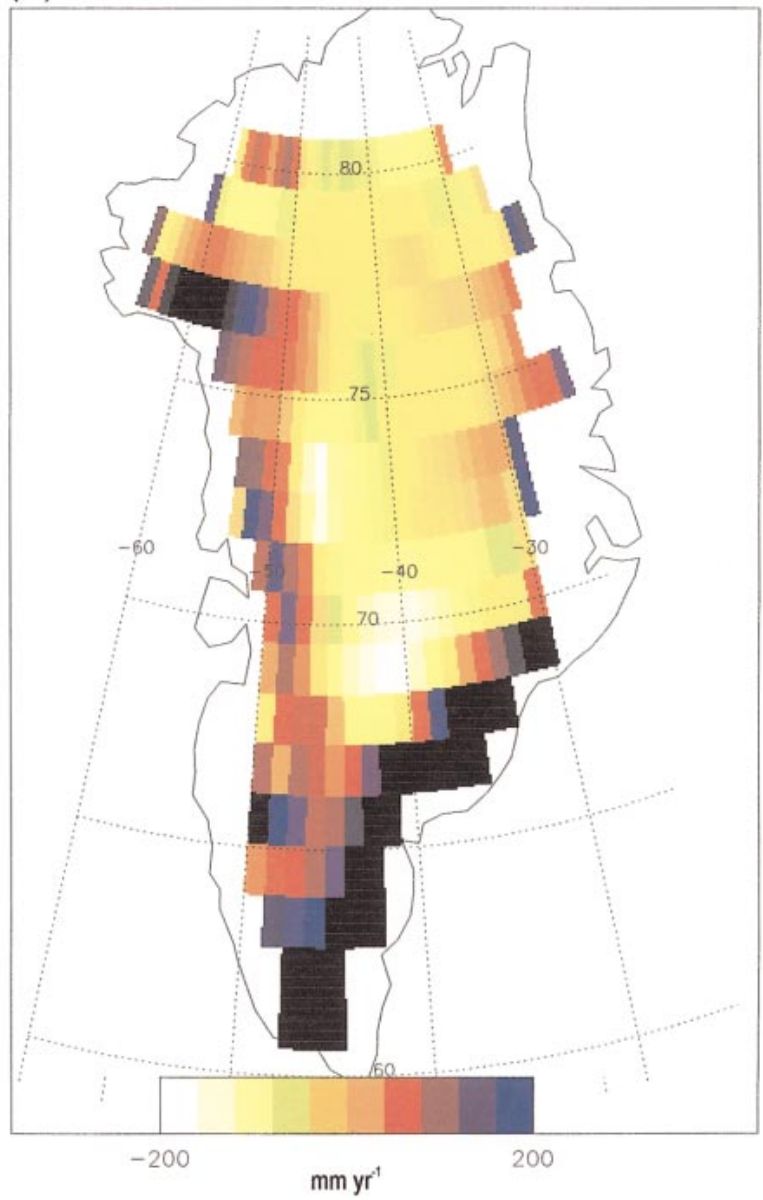

FIG. 4. (a) ECMWF analyses MAA (1979-98) for Greenland. (b) ECMWF analyses MAA (1979-98) minus Calanca snow accumulation. (c) Percentage difference of ECMWF analyses MAA (1979-98) relative to Calanca snow accumulation. (d) Underlying cumulative 20-yr change (from least squares linear regression trend) in 1979-98 ECMWF analyses MAA.

for evaporation/sublimation but not runoff) is likely to be similar to net accumulation well inland and high up (where there is little runoff). In the lower-elevation regions and near the GIS margin it is probably more likely to fall substantially between net and gross accumulation.

We obtained both these maps in digital form and remapped them to the ECMWF N80 $\left(\sim 1.125^{\circ}\right)$ grid, for comparison with our ECMWF-derived mean annual snow accumulation (MAA; 1979-98) map (Fig. 4a). Difference (ECMWF - comparison) and percentage difference [(ECMWF/comparison) 100 - 100] maps were produced (Figs. 4b,c). The Calanca map was used as the comparison simply because of its greater spatial resolution and hence easier translation (without having to interpolate for missing pixels) onto the ECMWF N80 grid.

It must be considered that the timescales and period on which the maps are based are quite different. The Calanca (updated Ohmura and Reeh) map is based on several hundred noncontemporaneous ice cores spanning, in some cases, much of the twentieth century.
Satellite data from 1973 to 1976 and 1979 were used to calculate firm emissivities for the Zwally and Giovinetto model, which was calibrated using coefficients from field data similar to those used by Ohmura and Reeh. On the other hand, our ECMWF MAA map is clearly based on a recent period of just $20 \mathrm{yr}$. It is possible that climatological changes over Greenland (e.g., related to the NAO), which may have occurred on a regional basis, may bias it relative to the two comparison maps.

All three Greenland snow accumulation distributions show broadly similar high values in the south and inland up the western side, with a secondary peak northeast of Jakobshavn, Greenland, at $\sim 71^{\circ} \mathrm{N}, 48^{\circ} \mathrm{W}$, while values to the northeast are much lower. Accumulation commonly reaches or exceeds $1 \mathrm{~m} \mathrm{yr}^{-1}$ in the southeast, due to both cyclonic and orographic influences (steep nearcoastal topography near the Icelandic low), and is typically $0.3-0.5 \mathrm{~m} \mathrm{yr}^{-1}$ up the western side. ECMWF MAA tends to be comparatively high (by $\geq 0.2 \mathrm{~m} \mathrm{yr}^{-1}$ ) in some lower/near-coastal areas, particularly in the 
(c)

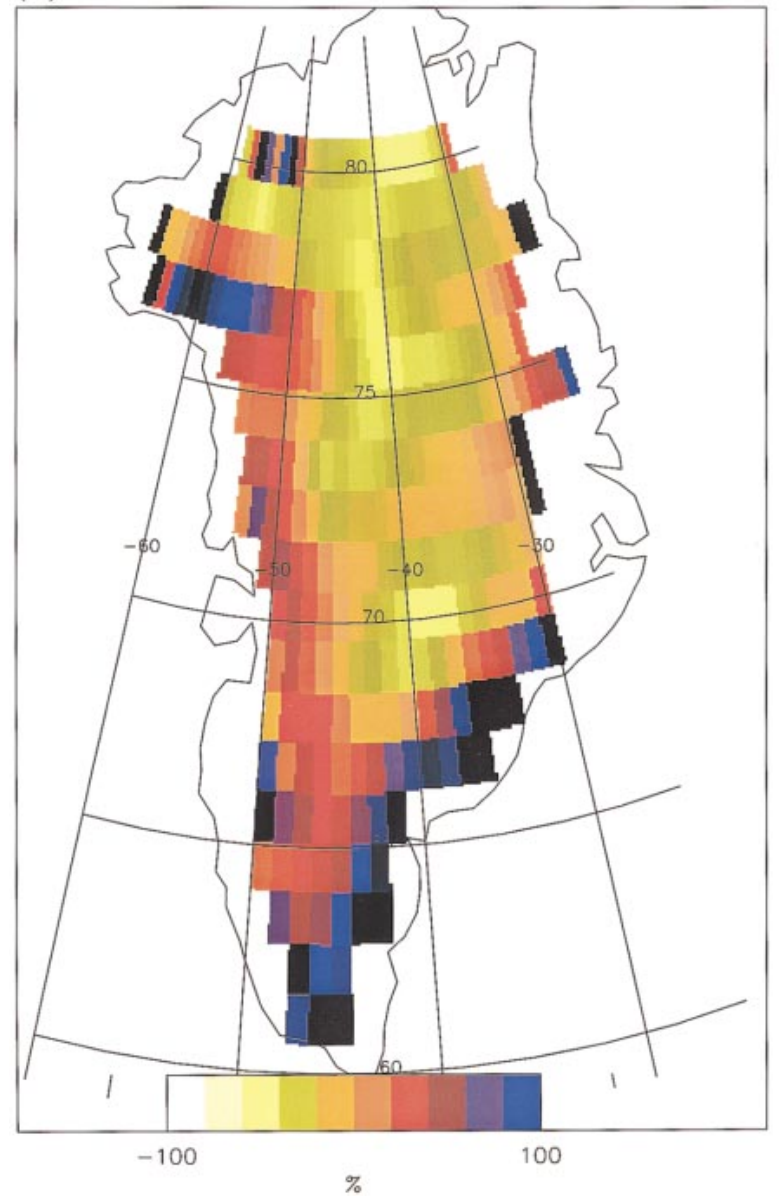

(d)

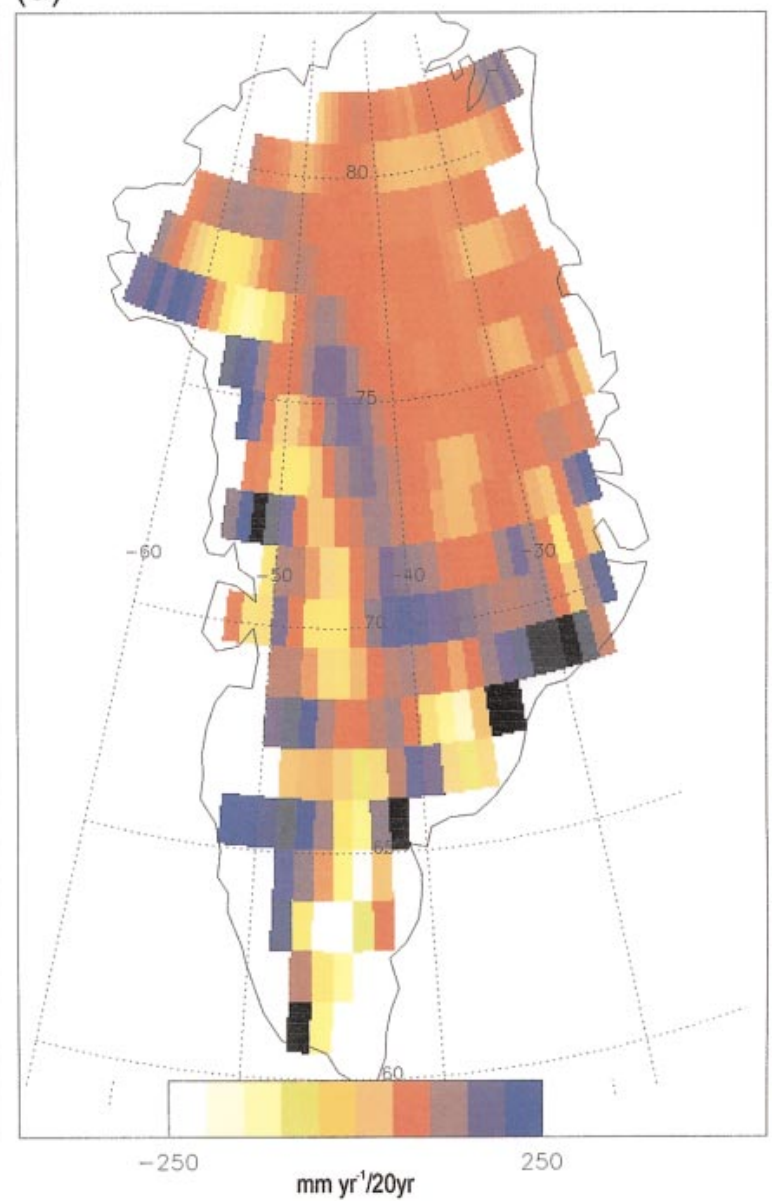

FIG. 4. (Continued)

southeast, where runoff (not considered) is likely to be appreciable (Fig. 4b). Much (more than two-thirds) of the southern area, south of $\sim 67^{\circ} \mathrm{N}$, has ECMWF values $\geq 0.1 \mathrm{~m} \mathrm{yr}^{-1}$ higher than in the Calanca map. However, ECMWF MAA is relatively low in parts of central Greenland (e.g., $<0.3 \mathrm{~m} \mathrm{yr}^{-1}$ around $70^{\circ} \mathrm{N}, 40^{\circ} \mathrm{W}$, compared with $\geq 0.4 \mathrm{~m} \mathrm{yr}^{-1}$ in the Calanca and Zwally/ Giovinetto maps). ECMWF MAA decreases to $\sim 0.06-$ $0.07 \mathrm{~m} \mathrm{yr}^{-1}$ around $78^{\circ} \mathrm{N}, 40^{\circ} \mathrm{W}$, which according to the anomaly map is too low by $\sim 40 \%$ (Fig. $4 \mathrm{c}$ ). The greatest percentage deficits $(\sim 50 \%)$ in ECMWF MAA are seen just east and northeast of $70^{\circ} \mathrm{N}, 40^{\circ} \mathrm{W}$.

The coastal/southern surplus (where precipitation and accumulation amounts are relatively large) and central/ central-northern deficit (which covers a much larger area) will tend to cancel when considering ECMWF island-averaged snow accumulation. The southern Greenland surplus is seen as a higher overall ECMWF modeled (than observed) accumulation in the results of McConnell et al. (2001).

We present a map of underlying cumulative 20-yr (1979-98) change in Greenland snow accumulation from ECMWF analyses (Fig. 4d), which we compare with Fig. 3-the map of ice thickening rate-in Thomas et al. (2000). These authors compared ice discharge with total snow accumulation over the higher-elevation $(>2$ $\mathrm{km}$ ) areas. They found that this zone was on average in mass balance over the past few decades, with substantial thinning in the southeast $\left(\sim 0.30 \mathrm{~m} \mathrm{yr}^{-1}\right)$ and northwest $\left(\sim 0.05 \mathrm{~m} \mathrm{yr}^{-1}\right)$ and substantial thickening in the southwest $\left(\sim 0.21 \mathrm{~m} \mathrm{yr}^{-1}\right)$ and northeast $(\sim 0.02 \mathrm{~m}$ $\left.\mathrm{yr}^{-1}\right)$. Their trend patterns agree quite well qualitatively with our cumulative change map, although our amounts of change are considerably lower (Fig. 4d). Apart from verifying the regional and temporal performance of our ECMWF-driven accumulation model, this result further supports the recent conclusion, referenced in the introduction, that accumulation changes are an important influence on mass balance and elevation changes in this high-elevation zone (McConnell et al. 2000a).

\section{b. Comparison with ice-core data}

We use data from 41 ice cores widely distributed across Greenland to quantitatively point validate our 
TABLE 4. Details (including site locations and periods) of other Greenland ice-core data used in this study. Taken from Ohmura et al. (1999), except * from Bolzan and Strobel (1994).

\begin{tabular}{lcccc}
\hline \hline \multicolumn{1}{c}{ Site } & $\begin{array}{c}\text { Lat } \\
\left({ }^{\circ} \mathrm{N}\right)\end{array}$ & $\begin{array}{c}\text { Long } \\
\left({ }^{\circ} \mathrm{W}\right)\end{array}$ & $\begin{array}{c}\text { Elev } \\
(\mathrm{m})\end{array}$ & Period \\
\hline T41 & 71.08 & 37.92 & 3153 & $1979-89$ \\
T31 (St. Centrale) & 70.92 & 40.63 & 2965 & $1981-89$ \\
T27 & 70.78 & 41.53 & 2872 & $1982-89$ \\
T21 & 70.55 & 43.03 & 2696 & $1982-89$ \\
T17 & 70.38 & 44.12 & 2534 & $1981-89$ \\
T13 & 70.23 & 44.98 & 2377 & $1982-89$ \\
T9 & 70.02 & 46.32 & 2112 & $1981-89$ \\
T5 & 69.87 & 47.27 & 1911 & $1983-89$ \\
T99 (GRIP/Summit) & 72.58 & 37.65 & 3230 & $1983-91$ \\
NST08 & 71.87 & 37.77 & 3220 & $1983-91$ \\
T47 & 71.2 & 35.95 & 3099 & $1983-91$ \\
T50 & 71.3 & 34.55 & 2984 & $1983-91$ \\
T53 (Jarl-Joset) & 71.35 & 33.47 & 2864 & $1983-91$ \\
T61 & 72.22 & 32.32 & 2812 & $1983-91$ \\
T66 & 72.48 & 30.77 & 2678 & $1983-91$ \\
Crawford Point & 69.88 & 46.98 & 2000 & $1982-94$ \\
Summit* & 72.31 & 37.91 & 3153 & $1979-86$ \\
\hline
\end{tabular}

ECMWF mean annual accumulation data (Tables 3 and 4). Some 24 of the ice-core datasets are from the NASA PARCA program while 16 others are taken from Ohmura et al. (1999) and the Summit cores from Bolzan and Strobel (1994). Figures 5 and 6 show the PARCA and other Greenland ice-core locations. Note that nearly all the cores were taken above 2-km elevation, where minimal surface melt runoff should make ECMWF-modeled and observed snow accumulation roughly comparable.

The first 11 listed PARCA sites (McConnell et al. 2000b) are quite widely scattered across Greenland but are generally situated on the intermediate plateau between the near-coastal regions and central ice dome. Site elevations range from $1973 \mathrm{~m}$ at site 11 to $2850 \mathrm{~m}$ at site 1 , with a mean height of $2375 \mathrm{~m}$. Six of the datasets from these sites are based on spatial averages of between two and five cores (McConnell et al. 2000b). The second group of (13) PARCA cores (the 1998 PARCA ice-core data) is more centrally located in a chevron shape a little south of the main ice dome. The mean height of these cores is a little greater at $2653 \mathrm{~m}$. Annual accumulation values were used from all these sites for varying periods but typically 10-20 yr to the late 1990s (Table 3).

The other principal set of central Greenland ice cores is for considerably earlier, shorter periods, generally in the 1980s (Ohmura et al. 1999). Elevations range from $1911 \mathrm{~m}$ (T5) to well over $3000 \mathrm{~m}$ for several cores. Only mean annual accumulations are available for these sites, which is still useful information but precludes a detailed temporal analysis with coincident model pixels. The Summit dataset (after Bolzan and Strobel 1994) is actually the mean of nine cores distributed in a $150 \times$ $150 \mathrm{~km}$ survey grid around this site and is therefore

TABLE 5. Comparison of PARCA ice-core accumulation (mean, SD, underlying cumulative change, and correlation coefficient $r$ ) with coincident and contemporaneous ECMWF accumulation (see Table 3 for site details and years used). Cumulative changes refer to individual core periods of length $N$ years. Bold " $r$ " values indicate a statistically significant (5\% level) correlation between the observed and modeled series.

\begin{tabular}{|c|c|c|c|c|c|c|c|c|}
\hline \multirow[b]{2}{*}{ Site } & \multicolumn{3}{|c|}{ Mean $\left(\mathrm{m} \mathrm{yr}^{-1}\right)$} & \multicolumn{2}{|c|}{$\mathrm{SD}\left(\mathrm{m} \mathrm{yr}^{-1}\right)$} & \multicolumn{2}{|c|}{$\begin{array}{l}\text { Cumulative change } \\
\left(\mathrm{m} \mathrm{yr}^{-1} \mathrm{~N} \mathrm{yr}^{-1}\right)\end{array}$} & \multirow{2}{*}{$\begin{array}{c}r \\
\text { Core- } \\
\text { ECMWF }\end{array}$} \\
\hline & Core & ECMWF & ECMWF/core & Core & ECMWF & Core & ECMWF & \\
\hline 1 & 0.651 & 0.692 & 1.063 & 0.096 & 0.170 & 0.095 & -0.226 & 0.411 \\
\hline 2 & 0.449 & 0.457 & 1.018 & 0.082 & 0.088 & 0.002 & -0.084 & 0.757 \\
\hline 3 & 0.613 & 0.552 & 0.900 & 0.141 & 0.147 & -0.103 & -0.102 & 0.125 \\
\hline 4 & 0.474 & 0.160 & 0.338 & 0.130 & 0.039 & 0.059 & 0.050 & 0.729 \\
\hline 5 & 0.144 & 0.104 & 0.722 & 0.037 & 0.031 & -0.079 & 0.008 & 0.100 \\
\hline 6 & 0.421 & 0.460 & 1.093 & 0.069 & 0.085 & -0.002 & 0.011 & 0.813 \\
\hline 7 & 0.422 & 0.330 & 0.782 & 0.078 & 0.064 & 0.026 & -0.044 & 0.563 \\
\hline 8 & 0.317 & 0.367 & 1.158 & 0.060 & 0.061 & -0.020 & -0.032 & 0.724 \\
\hline 9 & 0.306 & 0.307 & 1.003 & 0.048 & 0.049 & -0.003 & -0.048 & 0.677 \\
\hline 10 & 0.345 & 0.350 & 1.014 & 0.069 & 0.073 & 0.069 & 0.048 & 0.714 \\
\hline 11 & 0.136 & 0.195 & 1.434 & 0.019 & 0.044 & 0.006 & -0.002 & 0.304 \\
\hline Mean & 0.389 & 0.361 & 0.957 & 0.075 & 0.077 & 0.005 & -0.038 & 0.538 \\
\hline 6345 & 0.319 & 0.677 & 2.122 & 0.065 & 0.177 & 0.027 & -0.282 & 0.344 \\
\hline 6745 & 0.361 & 0.340 & 0.942 & 0.085 & 0.091 & -0.062 & 0.002 & 0.453 \\
\hline 6839 & 0.385 & 0.189 & 0.491 & 0.091 & 0.043 & 0.077 & 0.047 & 0.697 \\
\hline 6841 & 0.475 & 0.383 & 0.806 & 0.099 & 0.094 & 0.017 & -0.070 & 0.617 \\
\hline 6938 & 0.359 & 0.208 & 0.579 & 0.062 & 0.035 & -0.011 & -0.035 & 0.648 \\
\hline 6939 & 0.334 & 0.154 & 0.461 & 0.056 & 0.063 & 0.014 & 0.115 & 0.360 \\
\hline 6941 & 0.384 & 0.201 & 0.523 & 0.072 & 0.062 & 0.027 & 0.066 & 0.616 \\
\hline 6943 & 0.400 & 0.271 & 0.678 & 0.088 & 0.078 & -0.025 & 0.035 & 0.762 \\
\hline 6945 & 0.450 & 0.347 & 0.771 & 0.107 & 0.109 & -0.030 & -0.046 & 0.785 \\
\hline 7145 & 0.429 & 0.362 & 0.844 & 0.072 & 0.083 & -0.012 & -0.090 & 0.716 \\
\hline 7245 & 0.361 & 0.249 & 0.690 & 0.048 & 0.040 & 0.009 & -0.001 & 0.841 \\
\hline 7345 & 0.286 & 0.177 & 0.619 & 0.049 & 0.041 & 0.047 & 0.079 & 0.664 \\
\hline 736472 & 0.289 & 0.256 & 0.886 & 0.048 & 0.041 & 0.019 & -0.015 & 0.437 \\
\hline Mean & 0.372 & 0.293 & 0.801 & 0.072 & 0.074 & 0.007 & -0.015 & 0.611 \\
\hline
\end{tabular}




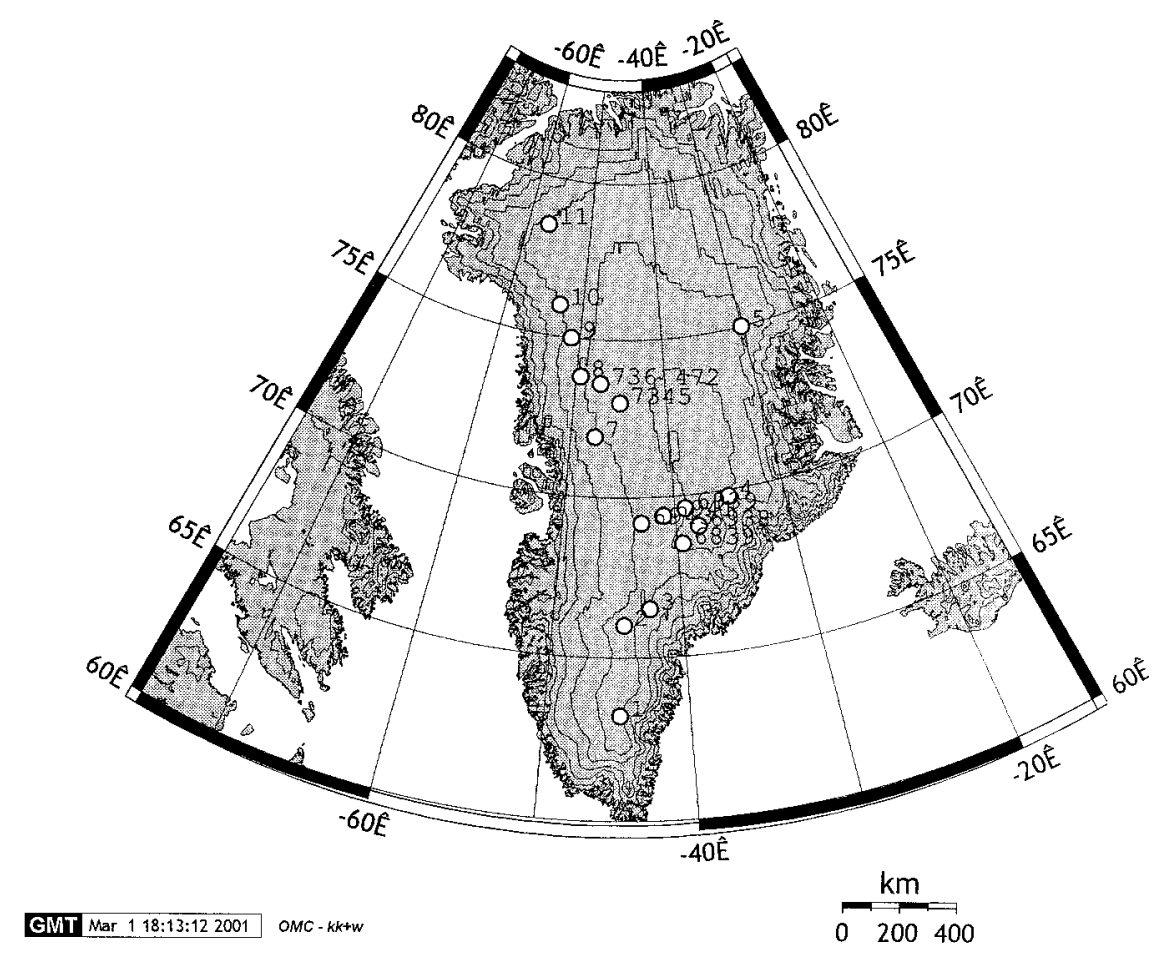

FIG. 5. Map showing PARCA ice-core sites used in this study.

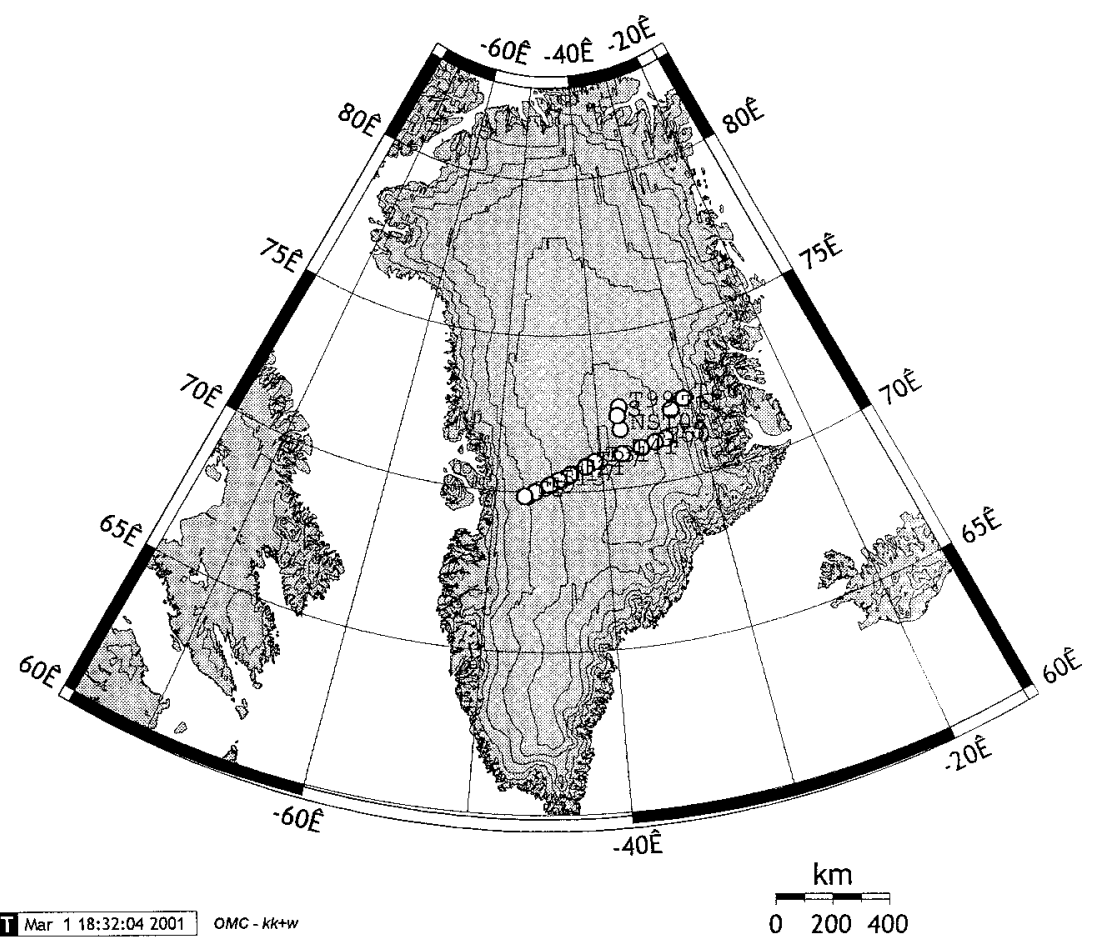

FIG. 6. Map showing other Greenland ice-core sites used in this study. 
TABLE 6. Comparison of other Greenland ice-core accumulation [only mean data $\left(\mathrm{m} \mathrm{yr}^{-1}\right)$ available] with coincident and contemporaneous ECMWF accumulation (see Table 4 for site details and years used).

\begin{tabular}{lccc}
\hline \hline \multicolumn{1}{c}{ Site } & Core & ECMWF & ECMWF/core \\
\hline T41 & 0.243 & 0.134 & 0.551 \\
T31 (St. Centrale) & 0.349 & 0.177 & 0.507 \\
T27 & 0.402 & 0.209 & 0.520 \\
T21 & 0.430 & 0.274 & 0.637 \\
T17 & 0.444 & 0.360 & 0.811 \\
T13 & 0.452 & 0.434 & 0.960 \\
T9 & 0.424 & 0.497 & 1.172 \\
T5 & 0.461 & 0.545 & 1.182 \\
T99 (GRIP/Summit) & 0.188 & 0.151 & 0.803 \\
NST08 & 0.229 & 0.162 & 0.707 \\
T47 & 0.221 & 0.128 & 0.579 \\
T50 & 0.227 & 0.130 & 0.573 \\
T53 (Jarl-Joset) & 0.232 & 0.137 & 0.591 \\
T61 & 0.187 & 0.136 & 0.727 \\
T66 & 0.168 & 0.165 & 0.982 \\
Crawford Point & 0.480 & 0.506 & 1.054 \\
Summit & 0.213 & 0.149 & 0.700 \\
Mean & 0.315 & 0.253 & 0.768 \\
\hline
\end{tabular}

highly appropriate for comparison with the ECMWF analyses results. Annual accumulation values are available for Summit but only for the period 1979-86.

There is an inherent spatial uncertainty in comparing an ice-core site with a coincident ECMWF pixel; to counter this, averages from several cores taken locally (i.e., across several square kilometers) are used wherever possible (see above). Validation results are based on contemporaneous data; in all cases the time periods of the modeled data are exactly matched to the ice-core time periods. This at least solves the problem inherent in the above discussion (3a) when comparing accumulation maps based on different epochs.

The results of the ECMWF-ice-core accumulation comparisons are shown in Tables 5 and 6 . These show observed (core) and modeled (ECMWF) means, SDs and trends, and core-ECMWF $r$ values for individual core sites for the periods listed in Tables 3 and 4.

Note the excellent agreement in the observed/modeled mean values of the first 11 PARCA cores, with ECMWF accumulation $\left(0.361 \mathrm{~m} \mathrm{yr}^{-1}\right) \sim 96 \%$ of observed $\left(0.389 \mathrm{~m} \mathrm{yr}^{-1}\right)$ (Table 5). There is also excellent agreement in the mean SDs $\left(0.075 \mathrm{~m} \mathrm{yr}^{-1}\right.$ for the cores and $0.077 \mathrm{~m} \mathrm{yr}^{-1}$ for ECMWF accumulation), indicating that our ECMWF-driven model realistically captures the scale of interannual accumulation fluctuations gleaned from the cores. The ECMWF variability may be too high, however. The SDs from atmospheric methods should generally be less than the ice-core results because the former are spatially averaged over large distances and the latter are subject to high noise levels from spatial variability due to sastrugi and topographic undulations, from uncertainties in dating of the core, and so on. There are minor differences in observed and modeled trends. Most trends for individual sites, and mean trends for all the sites, are quite modest and insignificant relative to their respective SDs. Correlation coefficients between the annual core and ECMWF accumulation values are $t$-tested significant for 8 out of the 11 sites. These data show that our ECMWF-driven accumulation model successfully captures the absolute amount of observed snow accumulation, and reasonably portrays its spatial and temporal variations, on the intermediate plateau of Greenland.

Table 7 shows accumulation data from the same 11 PARCA cores but this time for the period 1985-96 (except for sites 8 and 11: 1985-92). Values from the ChenBromwich $(\mathrm{C}-\mathrm{B})$ enhanced dynamic precipitation retrieval method are shown alongside core and ECMWF accumulation values. The comparison shows a considerable underread of $\mathrm{C}-\mathrm{B}$ mean and SD values $(0.235$ and $\left.0.034 \mathrm{~m} \mathrm{yr}^{-1}\right)$ relative to the core $(0.391$ and 0.073 $\left.\mathrm{m} \mathrm{yr}^{-1}\right)$ and ECMWF $\left(0.361\right.$ and $\left.0.080 \mathrm{~m} \mathrm{yr}^{-1}\right)$ mean and SD values. Only site 5 has a (barely) notable (down-

TABLE 7. Comparison of McConnell et al. (2000) PARCA ice-core accumulation (mean, SD, underlying cumulative change, and correlation coefficient $r$ ) with coincident and contemporaneous ECMWF-modeled accumulation and C-B-modeled precipitation. Period 1985-96 except for sites 8 and 11 (1985-92). Cumulative changes refer to individual core periods of length $N$ years. Bold " $r$ " values indicate a statistically significant (5\% level) correlation between the observed and modeled series.

\begin{tabular}{|c|c|c|c|c|c|c|c|c|c|c|c|}
\hline \multirow[b]{3}{*}{ Site } & \multirow{2}{*}{\multicolumn{3}{|c|}{ Mean $\left(\mathrm{m} \mathrm{yr}^{-1}\right)$}} & \multirow{2}{*}{\multicolumn{3}{|c|}{$\mathrm{SD}\left(\mathrm{m} \mathrm{yr}^{-1}\right)$}} & \multirow{2}{*}{\multicolumn{3}{|c|}{ Cumulative change $\left(\mathrm{m} \mathrm{yr}^{-} \mathrm{N} \mathrm{yr}^{-1}\right)$}} & \multicolumn{2}{|c|}{$r$} \\
\hline & & & & & & & & & & Core- & \\
\hline & Core & ECMWF & $\mathrm{C}-\mathrm{B}$ & Core & ECMWF & $\mathrm{C}-\mathrm{B}$ & Core & ECMWF & $\mathrm{C}-\mathrm{B}$ & ECMWF & Core-C-B \\
\hline 1 & 0.684 & 0.682 & 0.256 & 0.092 & 0.208 & 0.037 & -0.087 & -0.435 & -0.087 & 0.606 & 0.566 \\
\hline 2 & 0.445 & 0.444 & 0.221 & 0.081 & 0.085 & 0.035 & 0.003 & -0.128 & -0.061 & 0.665 & 0.252 \\
\hline 3 & 0.593 & 0.544 & 0.416 & 0.140 & 0.156 & 0.061 & -0.041 & -0.155 & -0.070 & 0.149 & 0.351 \\
\hline 4 & 0.473 & 0.164 & 0.220 & 0.090 & 0.037 & 0.024 & 0.064 & 0.044 & -0.002 & 0.656 & 0.750 \\
\hline 5 & 0.127 & 0.101 & 0.074 & 0.021 & 0.023 & 0.023 & -0.024 & 0.024 & 0.039 & -0.027 & -0.004 \\
\hline 6 & 0.425 & 0.465 & 0.248 & 0.074 & 0.089 & 0.038 & -0.015 & -0.004 & 0.034 & 0.839 & 0.802 \\
\hline 7 & 0.428 & 0.329 & 0.347 & 0.087 & 0.069 & 0.045 & 0.009 & -0.067 & 0.002 & 0.590 & 0.855 \\
\hline 8 & 0.314 & 0.368 & 0.193 & 0.070 & 0.062 & 0.028 & -0.005 & -0.042 & -0.001 & 0.817 & 0.886 \\
\hline 9 & 0.306 & 0.305 & 0.190 & 0.052 & 0.046 & 0.025 & 0.009 & -0.065 & 0.048 & 0.556 & 0.466 \\
\hline 10 & 0.364 & 0.364 & 0.310 & 0.072 & 0.069 & 0.034 & 0.012 & 0.026 & 0.074 & 0.644 & 0.444 \\
\hline 11 & 0.140 & 0.207 & 0.114 & 0.019 & 0.036 & 0.019 & 0.000 & -0.070 & 0.002 & 0.216 & 0.355 \\
\hline Mean & 0.391 & 0.361 & 0.235 & 0.073 & 0.080 & 0.034 & -0.007 & -0.079 & -0.002 & 0.519 & 0.520 \\
\hline
\end{tabular}


ward) trend in core accumulation (only slightly $>1 \mathrm{SD}$ ), whereas the ECMWF and C-B models both suggest slight upward trends for this site. Both models show accumulation trends for individual sites where no such significant trend (based on the SD) is apparent from the core data, for example, substantial downward trends at sites 1 and 2. However, the number of years is too small to read anything meaningful into these findings. Moreover, trends averaged for all the sites are insignificant from all three (core, ECMWF, and C-B) methods. The core data-model output correlation comparison shows similar performances of the ECMWF accumulation and C-B precipitation models.

For 8 out of the 11 core averages, mean annual accumulation agreed more closely with ECMWF-modeled accumulation than C-B-modeled precipitation (Fig. 7). The cores at site 4 are the most notable exceptions, but even in these cases, C-B does not provide a much better agreement than ECMWF (both show a shortfall of $>50 \%$ ). Site 4 is an outlier to the east of the main ice dome in central-eastern Greenland (Fig. 5). A possible explanation may be that orographic deficiencies in the climate models, namely, over high-coastal mountains in the west and southwest, exacerbate the precipitation shadow effect in this part of the island.

For the second set of PARCA cores (in central Greenland), the ECMWF-driven model still did a reasonable job of picking up temporal fluctuations observed in the ice-core data (e.g., note the similarity of the SDs and the generally high core-model $r$ values). However, it tended to give accumulation values $\sim 80 \%$ of observed (Table 5). Also, the more uneven (ECMWF/core) values for individual sites suggest that spatial variability was not so well modeled as for the first (outer) group of PARCA cores. However, there is inherently greater spatial uncertainty because this second set of cores consists entirely of individual sites without any clusters. Mean observed and modeled trend values for these sites are negligible.

The third set of cores (also for central Greenland, albeit a wider traverse) gives a similar picture, with mean modeled accumulation $\sim 77 \%$ of observed, including $\sim 70 \%$ of spatially averaged Summit core accumulation (ECMWF accumulation $0.149 \mathrm{~m} \mathrm{yr}^{-1}$ as against $0.213 \mathrm{~m} \mathrm{yr}^{-1}$ for the core average; Table 6). The individual annual data available for Summit give identical observed and modeled SD values (0.029 $\left.\mathrm{m} \mathrm{yr}^{-1}\right)$ and similar observed and modeled cumulative 8-yr changes of, respectively, 0.029 and $0.035 \mathrm{~m} \mathrm{yr}^{-1}(8$ $\mathrm{yr})^{-1}$, neither of which are really significant, especially considering the short record.

The results from the last two sets of cores confirm the underestimation of precipitation/accumulation by the ECMWF analyses/model inland of the core sites of McConnell et al. (2000b), reported by Bromwich et al. (1998).

\section{Conclusions}

ECMWF surface climate analyses are useful for studying interannual variations of precipitation and snow accumulation across the GIS-provided knowledge of their shortcomings is borne in mind. However, due mainly to model changes (especially a suspected change in the boundary layer treatment in later operational analyses), considerable caution should be exercised if using ECMWF analyses by themselves to interpolate climatic_-particularly temperature - trends, as this could give very misleading results. The NCEPNCAR reanalysis is probably more internally consistent for this purpose. ECMWF-analyzed 2-m temperatures, which the authors corrected using an improved orography scheme, were mostly $\sim 5^{\circ}-6^{\circ} \mathrm{C}$ colder in winter than NCEP-NCAR reanalysis temperatures (also corrected for orography errors), but this difference became nominal as they rose after 1995. This is thought to have been due to changes in the boundary layer parameterization in the ECMWF scheme, and suggests that the earlier ECMWF temperatures need further adjustment for this effect.

Our extensive validation with ice-core data shows that the ECMWF analyses give a good first-order approximation of the spatial distribution and temporal variation of snow accumulation over Greenland. The analyses yield accumulation amounts for the "intermediate" inland plateau that are more realistic than precipitation from (the current version of) the $\mathrm{C}-\mathrm{B}$ model; the latter is substantially too "dry" in this area. However, in common with $\mathrm{C}-\mathrm{B}$ model precipitation, ECMWF accumulation is too low over central and central-northern areas, typically by $\sim 20 \%-30 \%$ in central Greenland. Overall, it is not apparent that the published $\mathrm{C}-\mathrm{B}$ model results are superior. Our analysis of the higher-resolution ECMWF data suggests that these are among the best available estimates of Greenland precipitation and snow accumulation, and at the very least show significant skill over Greenland. The broad agreement in regional patterns between our cumulative change in accumulation map and a recent map of ice thickening rate (Thomas et al. 2000) is also very encouraging. It is clear that the potential benefits of ECMWF-forecast precipitation and modeled accumulation should not be ignored.

Based on a simple statistical analysis, we conclude that from 1979 to 1998 there were no statistically significant underlying trends in Greenland-averaged annual-and most monthly-precipitation and snow accumulation (the latter for elevations $>2 \mathrm{~km}$ ). However, pooling evidence from both the ECMWF and NCEPNCAR analyses, there may well have been a slight but nonsignificant $\left[\sim 0.5^{\circ} \mathrm{C}(20 \mathrm{yr})^{-1}\right]$ increase in annual surface air temperature, most of which occurred in autumn $\left[\sim 2^{\circ}-4^{\circ} \mathrm{C}(20 \mathrm{yr})^{-1}\right]$, which was significant. Accompanying this, there were marginally significant underlying precipitation increases in September and October over the $20 \mathrm{yr}$. 


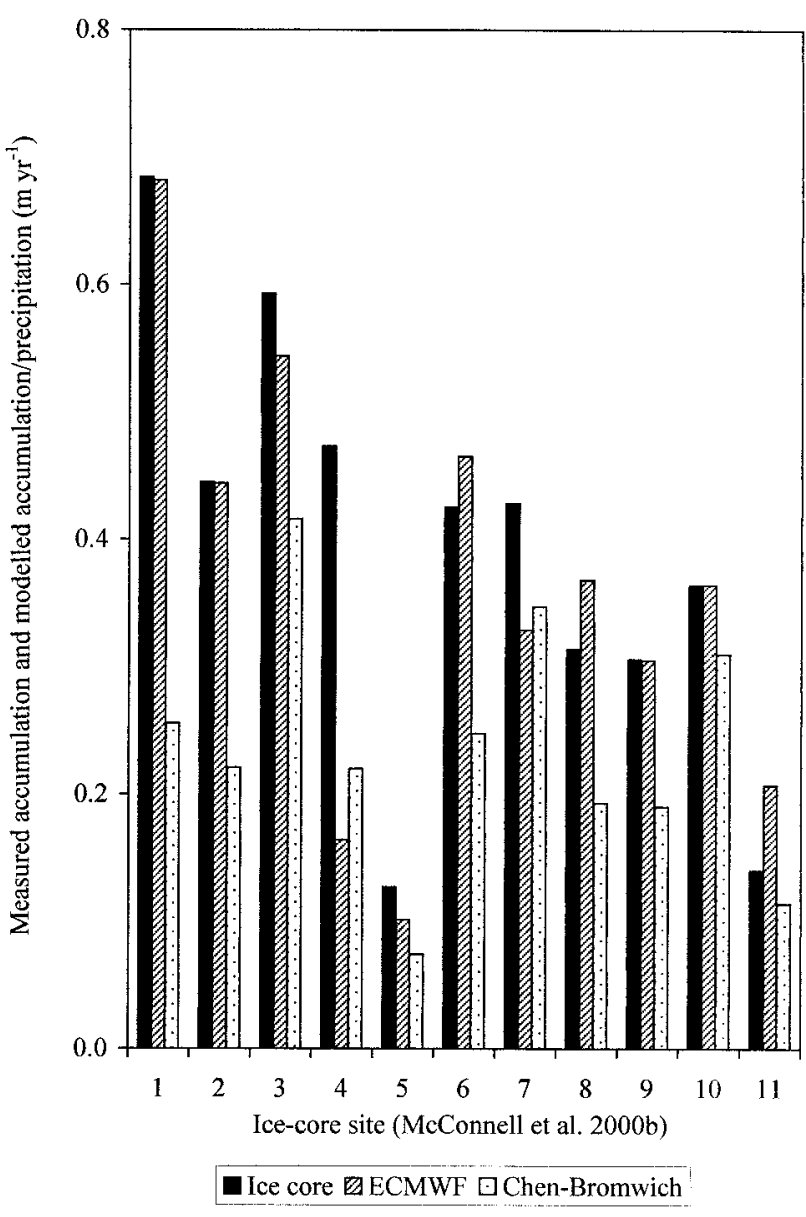

FIG. 7. Mean annual (mainly 1985-96) Greenland ice-core accumulation (based on core means where available) compared with ECMWF-modeled accumulation and $\mathrm{C}-\mathrm{B}$ modeled precipitation, for the first 11 PARCA core sites.

Much further work is under way compiling and comparing promising precipitation/accumulation retrieval techniques. These include improved versions of the $\mathrm{C}-$ B model (D. H. Bromwich 1999, personal communication) and other enhanced dynamic precipitation retrieval methods. Forecast fields from ECMWF operational analyses (which were performed at T213 spectral resolution since September 1991, and T319 more recently), available to the authors on an N160 $\left[\left(\sim 0.55^{\circ}\right)^{2}\right]$ grid, are also being considered. A particularly promising future contender is ERA40 (the "second-generation" ECMWF reanalysis), which is expected to incorporate improved parameterizations of ice sheet climate, and selected years/fields from this may be available from mid-2001 (P. Kållberg 2001, personal communication). ECMWF-modeled accumulation should be very useful for helping to constrain the SMB of the GIS, especially when used in conjunction with a suitable runoff/retention model (e.g., Janssens and Huybrechts 2000). Equally important will be the validation of all these new mod- el results through extended ice-core data, including those being collected as part of the PARCA program.

Acknowledgments. We thank Pierluigi Calanca, Mario Giovinetto, and Jay Zwally for providing their Greenland accumulation maps; Kees van der Veen for supplying Summit ice-core data; Anton Beljaars, Per Kållberg, and Pedro Viterbo for information on ECMWF climate analyses; and David Bromwich, Mario Giovinetto, and Brad Murphy for useful advice. This research was supported by NERC (UK) Grant GR3/11186 to University of Reading, and by NASA Grants NAG55031 and NAG5-6779 to the Desert Research Institute through The University of Arizona.

\section{REFERENCES}

Appenzeller, C., J. Schwander, S. Sommer, and T. F. Stocker, 1998: The North Atlantic Oscillation and its imprint on precipitation and ice accumulation in Greenland. Geophys. Res. Lett., 25, $1939-1942$.

Berrisford, P., R. Brugge, D. Li, and L. Steenman-Clark, 1998: Diagnosis of the ECMWF Re-Analysis dataset by the Centre for Global Atmospheric Modelling. UGAMP Tech. Rep. 48, GCAM, University of Reading, Reading, United Kingdom, 13 pp.

Bolzan, J. F., and M. Strobel, 1994: Accumulation-rate variations around Summit, Greenland. J. Glaciol., 40, 56-66.

Braithwaite, R. J., 1994: Thoughts on monitoring the effects of climate change on the surface elevation of the Greenland Ice Sheet. Global. Planet. Change, 9, 251-261.

Bromwich, D. H., 1999: Invited Speaker-Perspective on reanalyses from polar applications. Extended Abstracts; WCRP 2nd Int. Conf. on Reanalyses Abstract Digest, Wokefield Park, Reading, United Kingdom, WCRP, 48.

_ , F. M. Robasky, R. A. Keen, and J. F. Bolzan, 1993: Modeled variations of precipitation over the Greenland Ice Sheet. $J$. Climate, 6, 1253-1268.

__ R. I. Cullather, Q.-S. Chen, and B. M. Csathó, 1998: Evaluation of recent precipitation studies for Greenland Ice Sheet. J. Geophys. Res., 103, 26 007-26 024.

_- Q.-S. Chen, Y. Li, and R. I. Cullather, 1999: Precipitation over Greenland and its relation to the North Atlantic Oscillation. $J$. Geophys. Res., 104, 22 103-22 115.

_ _ R. I. Cullather, and M. C. Serreze, 2000: Reanalyses depictions of the Arctic atmospheric moisture budget. The Freshwater Budget of the Arctic Ocean, E. Lyn Lewis, Ed., Kluwer Academic Publishers, 163-196.

Calanca, P., H. Gilgen, S. Ekholm, and A. Ohmura, 2000: Gridded temperature and accumulation distributions for Greenland for use in cryospheric models. Ann. Glaciol., 31, 118-120.

Chen, Q.-S., D. H. Bromwich, and L. Bai, 1997: Precipitation over Greenland retrieved by a dynamic method and its relation to cyclonic activity. J. Climate, 10, 839-870.

Cullather, R. I., D. H. Bromwich, and M. C. Serreze, 2000: The atmospheric hydrologic cycle over the Arctic basin from reanalyses. Part I: Comparison with observations and previous studies. J. Climate, 13, 923-937.

ECMWF, 1995: User Guide to ECMWF Products Edition 2.1. Meteorological Bull. M3.2, European Centre for Medium-Range Weather Forecasts, Reading, United Kingdom, 71 pp.

Genthon, C., and A. Braun, 1995: ECMWF analyses and predictions of the surface climate of Greenland and Antarctica. J. Climate, $\mathbf{8}, 2324-2332$.

Gibson, J. K., P. Kållberg, S. Uppala, A. Hernandez, A. Nomura, and E. Serrano, 1997: ECMWF Re-Analysis Project Rep. Series 1. ERA description. European Centre for Medium-Range Weather Forecasts, Reading, United Kingdom, 72 pp. 
Hanna, E., and P. Valdes, 2001: Validation of ECMWF (re)analysis surface climate data, 1979-1998, for Greenland and implications for mass balance modelling of the Ice Sheet. Int. J. Climatol., 21, 171-195.

Houghton, J. T., L. G. Meira Filho, B. A. Callander, N. Harris, A. Kattenberg, and K. Maskell, Eds., 1996: Climate Change 1995: The Science of Climate Change. Cambridge University Press, $572 \mathrm{pp}$.

Hvidberg, C. S., 2000: When Greenland ice melts. Nature, 404, 551552 .

Janssens, I., and P. Huybrechts, 2000: The treatment of meltwater retention in mass-balance parameterizations of the Greenland ice sheet. Ann. Glaciol., 31, 133-140.

Kållberg, P., 1997: ECMWF Re-Analysis Project Rep. Series 2. Aspects of the Re-Analysed Climate. European Centre for MediumRange Weather Forecasts, Reading, United Kingdom, 89 pp.

Krabill, W., and Coauthors, 2000: Greenland Ice Sheet: High-elevation balance and peripheral thinning. Science, 289, 428-430.

McConnell, J. R., R. J. Arthern, E. Mosley-Thompson, C. H. Davis, R. C. Bales, R. Thomas, J. F. Burkhart, and J. D. Kyne, 2000a: Changes in Greenland ice sheet elevation attributed primarily to snow accumulation variability. Nature, 406, 877-879.

— E. Mosley-Thompson, D. H. Bromwich, R. C. Bales, and J. D. Kyne, 2000b: Interannual variations of snow accumulation on the Greenland Ice Sheet (1985-1996) New observations versus model predictions. J. Geophys. Res., 105, 4039-4046.

, G. Lamorey, E. Hanna, E. Mosley-Thompson, R. C. Bales, D.
Belle-Oudry, and J. D. Kyne, 2001: Annual net snow accumulation over southern Greenland from 1975 to 1998. J. Geophys. Res., in press.

Ohmura, A., and N. Reeh, 1991: New precipitation and accumulation maps for Greenland. J. Glaciol., 37, 140-148.

__, P. Calanca, M. Wild, and M. Anklin, 1999: Precipitation, accumulation and mass balance of the Greenland Ice Sheet. $Z$. Gletsch. Glazialgeol., 35, 1-20.

Stendel, M., and L. Bengtsson, 1999: How certain are recent temperature trends from reanalyses? Extended Abstracts, WCRP 2nd Int. Conf. on Reanalyses Abstract Digest, Workefield Park, Reading, United Kingdom, WCRP, 69.

Thomas, R., T. Akins, B. Csatho, M. Fahnestock, P. Gogineni, C. Kim, and J. Sonntag, 2000: Mass balance of the Greenland Ice Sheet at high elevations. Science, 289, 426-428.

van der Veen, C. J., and J. F. Bolzan, 1999: Interannual variability in net accumulation on the Greenland Ice Sheet: Observations and implications for mass balance measurements. J. Geophys. Res., 104, 2009-2014.

Viterbo, P., and A. K. Betts, 1999: Impact on ECMWF forecasts of changes to the albedo of the boreal forests in the presence of snow. J. Geophys. Res., 104, 27 803-27 810.

__ A. C. M. Beljaars, J.-F. Mahfouf, and J. Teixeira, 1999: The representation of soil moisture freezing and its impact on the stable boundary layer. Quart. J. Roy. Meteor. Soc., 125, 24012426.

Zwally, H. J., and M. B. Giovinetto, 2000: Spatial distribution of net surface mass balance on Greenland. Ann. Glaciol., 31, 126-132. 